\title{
Transrectal Ultrasonography Guided Prostate Biopsy in Evaluating Prostate Cancer with Histopathological Evaluation and Prostate Specific Antigen Correlation
}

\author{
Vishwanath Reddy¹, Devadasa Acharya ${ }^{2}$, Altaf Khan³ ${ }^{3}$ Renuka Patil ${ }^{4}$
}

\author{
${ }^{1}$ Assistant Professor, Department of Radiology, Yenepoya Medical College, Mangalore, Karnataka, India. ${ }^{2}$ Professor \\ and HOD, Department of Radiology, Yenepoya Medical College, Mangalore, Karnataka, India. ${ }^{3}$ Associate Professor, \\ Department of Urology, Yenepoya Medical College, Mangalore, Karnataka, India. ${ }^{4}$ Assistant Professor, \\ Department of Pathology, Yenepoya Medical College, Mangalore, Karnataka, India.
}

\section{ABSTRACT}

\section{BACKGROUND}

Prostate cancer is the second most common cause of cancer related deaths among men in the United States. In India, prostate cancer affects 4-5 men per 100,000 population ${ }^{1}$. Although it is a common disease, it is slow to manifest clinical signs. It is estimated that $30 \%$ of men over 45 yrs, harbor latent prostate cancer and will remain latent until death. The objective of the study was to evaluate the role of Transrectal Ultrasound (TRUS) guided biopsy with histopathological evaluation (HPE) in the detection of prostate cancer on the basis of elevated prostate-specific antigen levels (PSA).

\section{METHODS}

This prospective study was done on 36 patients who were referred to department of Radio-Diagnosis at Yenepoya Medical College Hospital, Mangalore for TRUS guided biopsy. TRUS guided biopsy was performed using the sextant core biopsy technique \& samples were sent to the department of pathology for histopathological evaluation and results were documented. Results were analysed based on frequency and percentage.

\section{RESULTS}

Prostatic diseases were more common in the older age group and incidence increases with age. Most of the patients in our study had grade II prostatic enlargement. Our study showed diagnostic rate of 6 core biopsy with serum PSA levels $4-10 \mathrm{ng} / \mathrm{ml}$ was in $11.1 \%$ cases, while the diagnostic rate was $0 \%$ with serum PSA levels $11-20 \mathrm{ng} / \mathrm{ml}, 16.75 \%$ levels of $21-30 \mathrm{ng} / \mathrm{ml}, 25 \%$ with levels of $41-50$ $\mathrm{ng} / \mathrm{ml}$ and diagnostic rate was $100 \%$ with serum PSA levels of $>51 \mathrm{ng} / \mathrm{ml}$, indicating strong correlation of PSA level with tumour diagnosis by TRUS guided biopsy.

\section{CONCLUSIONS}

TRUS guided sextant core biopsy is a safe and effective procedure in diagnosing prostate cancer and has high diagnostic rates for patients with PSA levels of $>50$ $\mathrm{ng} / \mathrm{ml}$ and gland volume between 30-50 cc.

\section{KEY WORDS}

TRUS, Guided Biopsy, Prostate Carcinoma
Corresponding Author: Dr. Vishwanath Reddy, Assistant Professor, Department of Radiology, Yenepoya Medical College, Derelakatte, Mangalore-575018, Karnataka, India.

E-mail:drvishwanathreddy@gmail.com

DOI: $10.14260 /$ jemds/2019/645

Financial or Other Competing Interests: None.

How to Cite This Article:

Reddy V, Acharya D, Khan A, et al. Transrectal ultrasonography guided prostate biopsy in evaluating prostate cancer with histopathological evaluation and prostate specific antigen correlation. J. Evolution Med. Dent. Sci. 2019;8(39): 2967-2971, DOI:
Submission 01-07-2019,

Peer Review 11-09-2019,

Acceptance 17-09-2019,

Published 30-09-2019. 


\section{BACKGROUND}

Prostate cancer is the second most common cause of cancer related deaths among men in the United States. In India, prostate cancer affects 4-5 men per 100,000 population. ${ }^{1}$ Although it is a common disease, it is slow to manifest clinical signs. It is estimated that $30 \%$ of men over $45 \mathrm{yrs}$, harbor latent prostate cancer and will remain latent until death. Unfortunately, anatomic location of prostate does not lend itself to straight forward examination. Historically, digital rectal examination has been the principal method of examination of prostate. However, this technique has its own limitation. The advent and refinement of ultrasound technology have provided a new method. Transrectal ultrasound with prostate biopsy, which is correlated with histopathological examination in conjunction with development of serum assays for PSA, has resulted in an impressive change in manner of diagnosis of prostate cancer. Transrectal ultrasonography (TRUS) is the most commonly used modality for imaging the prostate gland. It enables accurate determination of prostate size. When a cancer is visualized by ultrasonography, it is usually hypoechoic relative to normal tissue. However, the majority of hypoechoic foci detected by TRUS are not malignant; therefore, both its sensitivity and specificity are low. TRUS is mainly used to guide prostate biopsies. TRUS-guided biopsy is the most reliable method, at present, for accurate sampling of prostatic tissue in men considered at high risk for prostatic cancer. On the basis of digital rectal examination (DRE) and prostate specific antigen (PSA) findings, the TRUS-guided biopsy technique has become the accepted standard for prostate cancer diagnosis worldwide.

Transrectal ultrasound (TRUS) was initially described as a technique to evaluate rectal pathology. ${ }^{2}$ In 1963 , Takahashi and Ouchi $^{3}$ were the first to describe the use of TRUS to evaluate the prostate. However, medical ultrasound was rather primitive at this time, so the images created with this array were of such poor quality that they carried little medical utility. The first clinically applicable images of the prostate obtained with TRUS were described in 1967 by Watanabe ${ }^{4}$. They used a $3.5 \mathrm{MHz}$ transducer, which at that time was considered to be state of the art, to obtain images that were clinically meaningful. As ultrasound technology has become more refined, the use of TRUS in the evaluation of prostatic disease has increased. By the mid 1980s, the $7 \mathrm{MHz}$ ultrasound probe, which more clearly delineated the architecture of the prostate, had become a standard diagnostic instrument. Astraldi ${ }^{5}$ performed the first transrectal biopsy in 1937. In the mid 1980s, ${ }^{2}$ a transperineal ultrasound array was fitted with biopsy apparatus to allow direct correlation of the sonographic appearance of focal prostatic lesions with the histology of these lesions. Several years later, a spring-loaded core biopsy device was developed that operated via a TRUS probe. In 1987, 2 the first literature appeared describing the use of TRUS with transrectal biopsy. Since then, as ultrasound technology has become more refined, this technique has been described as a superior method of performing a core biopsy of the prostate. Since the initial reports of TRUS of the prostate by Wild and Reid, ${ }^{6}$ substantial technologic advances have improved the diagnostic capabilities of this modality. The current state of the art TRUS probe is a 5-8 $\mathrm{MHz}$ hand-held, high-resolution probe with multi-axial planar imaging capabilities, which has the capacity for both transverse and sagittal imaging of the prostate in real time. This probe can be fitted with an adapter that accepts the needle of a spring-loaded biopsy gun, thus allowing multiple cores of tissue to be easily obtained. The visualization provided by the new higher resolution transducers, coupled with the ability to direct the biopsy needle into various regions of interest and to provide uniform spatial separation of the areas to be sampled, has helped to make TRUS-guided prostate biopsy a standard technique in the diagnosis of prostate cancer.

Hodge et $\mathrm{al}^{7}$ published the landmark paper demonstrateing the efficacy of systemic sampling of prostate during TRUSguided biopsy. They were the first to report that systemic sampling of the prostate guided by TRUS improved the detection rate of prostate cancer over merely sampling hypoechoic or other lesions. By taking sextant(six-core) biopsies from the mid-lobe (Parasagital) of each side of prostate at the apex, middle and base, the cancer detection rate was superior to lesion directed biopsies.

We wanted to evaluate the role of Transrectal Ultrasound (TRUS) guided biopsy with histopathological evaluation (HPE) in the detection of prostate cancer on the basis of elevated prostate-specific antigen levels (PSA).

\section{METHODS}

This Prospective study was carried out on 36 patients over a period of 2 years from November 2014 to July 2016 in the Radiology Department. The patients who were referred with urinary symptoms suggestive of prostatic disease, were diagnosed using GE VOLUSON E8 ultrasound machine. This study includes patients with elevated PSA levels $(>4 \mathrm{ng} / \mathrm{ml}$ ) and prostatic lesions noted on TRUS. Informed consent was obtained from all participants, and a full explanation about the procedure risks involved and post procedure complications were explained to the patients.

All patients were subjected to DRE to ensure no rectal abnormalities, serum PSA testing, trans-abdominal ultrasound examination and TRUS, as well as biopsy. Before the procedure, the patients were given broad spectrum antibiotics to protect them against infection, they also underwent rectal enema to empty the rectal canal before the procedure to obtain clear images, and intra-rectal instillation of $20 \mathrm{ml}$ of local anaesthetic gel (Lidocaine 2\%) was used to alleviate pain and discomfort during the procedure.

A transrectal ultrasound probe $(6-12 \mathrm{MHz}$ range) with a combination of end-viewing and side-viewing transducer attached to GE VOLUSON E8 ultrasound machine was used. Local anaesthetic gel (Lidocaine $2 \%$ ) was applied over a latex condom applied onto the probe. All patients were examined in the left lateral decubitus position and it was well tolerated. A full urinary bladder was ensured to help in better visualization of the gland prior to the procedure.

The prostate was imaged in both axial and sagittal planes with assessment of volume, echogenicity, surface, calcification, and the presence of nodules. Each nodule was assessed for size, location in the gland, morphology, echogenicity, margin, and extent. Colour Doppler ultrasonography was then performed to assess colour mapping of the nodules and 
the surrounding prostate tissue. Sampling of the prostate was performed in the sagittal plane. Biopsies were obtained using automatic BARD MAX-CORE biopsy gun needle $(18 \mathrm{G} \times 25$ $\mathrm{cm})$. The most commonly used protocol was the "targeted plus systematic" sextant (Six-core) biopsy protocol and an additional sample from the suspicious lesion if noted were taken. After biopsy samples were obtained, they were persevered in formaldehyde solution and were sent to the Pathology section for histopathological analysis. The patient's rectum was then packed with lidocaine gel coated gauze packs to achieve haemostasis. After the procedure the patient was assessed for any complications and appropriate action was taken if necessary. Post procedure the patient was transferred to the urology/surgery ward for further observation and management.

\section{Inclusion Criteria}

1. Palpable mass on DRE (Digital Rectal Examination).

2. PSA (Prostate Specific Antigen) $>4 \mathrm{ng} / \mathrm{ml}$.

3. Nodule visible on TRUS.

4. Excessive PSA Velocity.

\section{Exclusion Criteria}

1. Prostatitis.

2. Uncorrectable bleeding diathesis (abnormal coagulation indices).

3. Uncooperative patient.

\section{Statistical Analysis}

The data were entered and analysed in SPSS. Frequency and Percentages of all the variables were computed. The chisquare test was used to compare the association presenting symptoms, prostate size and volume, echotexture, calcification, radiological findings, serum PSA levels. The results were considered statistically significant if the $p$-value was $<0.05$.

\section{RESULTS}

\section{Age Distribution}

Out of 36 patients studied 17 (47\%) subjects were between the age of $61-70 \mathrm{yrs}$. and least affected group was in the range of 40-50 yrs (8.5\%).Incidence of cancer in our study was found in subjects belonging to elderly group ranging between $60-80 y$ rs. In our study we found that the prostatic cancer was seen in elderly. The mean age was 65.86 yrs. These findings correlate with studies by Berry et al. ${ }^{11}$ In our study we found that the prostatic disease affected people above $40 \mathrm{yrs}$. with peak incidence being in the group 61-80yrs. Similar findings were noted in a study by Chukwudi and co-workers ${ }^{12}$ in which the patients' ages ranged from 30 to 86 .

\section{Correlation of Presenting Symptoms}

Our clinical data revealed that prevalence of symptoms of voiding difficulties was $78 \%$ and dysuria was $22 \%, 18(69 \%)$ out of 26 subjects with voiding difficulties were benign and 8 subjects (31\%) were malignant on HPE. Among patients with dysuria symptoms were $9(90 \%)$ out of 10 were benign and 1 $(10 \%)$ was malignant on HPE.In a study by Kazuhiro 13 the prevalence rates of urinary symptoms of voiding were $37.0 \%$, in our study it was $78 \%$. The $\mathrm{p}$ value for this correlation is not significant in our study.

\begin{tabular}{|c|c|c|c|c|}
\hline \multirow{2}{*}{\multicolumn{2}{|c|}{ Complaints }} & \multicolumn{2}{|c|}{ Histopathology } & \multirow{3}{*}{$\frac{\text { Total }}{26(100.0 \%)}$} \\
\hline & & \multirow{2}{*}{$\begin{array}{c}\text { Benign } \\
18(69.2 \%) \\
\end{array}$} & \multirow{2}{*}{$\begin{array}{c}\text { Malignant } \\
8(30.8 \%)\end{array}$} & \\
\hline Voiding & Count (\%) & & & \\
\hline Dysuria & Count (\%) & $9(90.0 \%)$ & $1(10.0 \%)$ & $10(100.0 \%)$ \\
\hline Total & Count (\%) & $27(75.0 \%)$ & $9(25.0 \%)$ & $36(100.0 \%)$ \\
\hline \multicolumn{5}{|c|}{ Table 1. Correlation of Presenting Symptoms with HPE } \\
\hline test, & $=0.197$ & & & \\
\hline
\end{tabular}

\section{Correlation of Prostate Size and Volume}

In our study out of 36 subjects $47 \%, 25 \%, 22 \%$ and $5 \%$ of subjects had prostate gland with volumes of 31-50 cc, 51-80 cc, $21-30 \mathrm{cc}$ and $>81 \mathrm{cc}$ and $77 \%$ of the malignancies were found in subjects having prostate volume of 31-50 cc on HPE correlation, which was statistically not significant. Study by Levine et al $^{14}$ demonstrated increased cancer rate detection was $43 \%, 27 \%$ and $24 \%$ of men with prostate volumes of $<30$ cc, $30-50 \mathrm{cc}$ and $>50 \mathrm{cc}$ respectively. Karakiewicz et al ${ }^{15}$ also evaluated the positive of sextant biopsy according to gland size. The positive rate of biopsy for glands of $20 \mathrm{cc}$ was $40 \%$ vs $10 \%$ for gland of $80-90 \mathrm{cc}$.

\begin{tabular}{|c|c|c|c|c|}
\hline \multirow{2}{*}{\multicolumn{2}{|c|}{ Prostate Size }} & \multicolumn{2}{|c|}{ Histopathology } & \multirow{2}{*}{ Total } \\
\hline & & \multirow{2}{*}{$\begin{array}{c}\text { Benign } \\
8(100.0 \%) \\
\end{array}$} & \multirow{2}{*}{$\begin{array}{c}\text { Malignant } \\
0(0.0 \%)\end{array}$} & \\
\hline $21-30 \mathrm{cc}$ & Count (\%) & & & $8(100.0 \%)$ \\
\hline $31-50 \mathrm{cc}$ & Count (\%) & $10(58.8 \%)$ & $7(41.2 \%)$ & $17(100.0 \%)$ \\
\hline $51-80$ cc & Count (\%) & $8(88.9 \%)$ & $1(11.1 \%)$ & $9(100.0 \%)$ \\
\hline$>81 \mathrm{cc}$ & Count (\%) & $1(50.0 \%)$ & $1(50.0 \%)$ & $2(100.0 \%)$ \\
\hline Total & Count (\%) & $27(75.0 \%)$ & $9(25.0 \%)$ & $36(100.0 \%)$ \\
\hline \multicolumn{5}{|c|}{ Table 2. Correlation of Prostate Size and Volume with HPE } \\
\hline $\mathrm{X}^{2}$ test, $\mathrm{p}$ & $e=0.085$ & & & \\
\hline
\end{tabular}

\section{Echotexture of the Prostate Gland}

In our study 27 (75\%) out of 36 subjects prostate had heterogeneous texture on TRUS and 9 subjects (25\%) prostate had homogenous echotexture. Most of patients in our study had heterogeneous echotexture. All the patients who had malignancy on HPE correlation had heterogeneous echotexture was statistically significant.

\section{Association between Calcification and Prostatic Malignancy}

Calcification was seen in both benign and malignant disease in the prostate in a study by Deland and his colleagues. ${ }^{16}$ In a study by Chan Gyu et al 17 they concluded that prostatic calcifications can aggravate lower urinary tract symptoms. In our study 8 subjects showed the presence of calcific foci in the transition and central zone which were benign on HPE correlation, statistically was not significant.

\section{Correlation between Radiological and Histological Diagnosis}

All the 36 subjects who were referred to us for TRUS guided biopsy were clinically diagnosed as carcinoma prostate. On radiological examination $33(92 \%)$ out of 36 subjects showed benign prostatic hyperplasia features, 3 subjects (8\%)were considered malignant based on solid hypoechoic lesion in the peripheral zone. On histopathological correlation 9 subjects (25\%) were found to have malignant features and 27 subjects (75\%) were found to have benign features. Out of 9 subjects who were found malignant, 8 had adenocarcinomas and 1 had PIN, out of 27 subjects who were found benign 20 (74\%) had benign prostatic hyperplasia and 7 patients $(26 \%)$ had 
benign prostatic hyperplasia with prostatitis. Statistically there was no significant correlation.

\begin{tabular}{|c|c|c|c|c|}
\hline \multirow{2}{*}{ Radiological Findings } & \multicolumn{2}{|c|}{ HPE Findings } & \multirow{2}{*}{ Total } \\
\cline { 3 - 4 } & & Benign & Malignant & \\
\hline Benign & Count (\%) & $25(75.8 \%)$ & $8(24.2 \%)$ & $33(100.0 \%)$ \\
\hline Malignant & Count (\%) & $2(66.7 \%)$ & $1(33.3 \%)$ & $3100.0 \%)$ \\
\hline Total & Count (\%) & $27(75.0 \%)$ & $9(25.0 \%)$ & $36(100.0 \%)$ \\
\hline \multicolumn{3}{|l}{ Table 3. Correlation between Radiological and HPE Findings } \\
\hline
\end{tabular}

\section{Correlation of PSA with HPE Findings}

Out of 36 patients 9 patients who were found to be malignant 6 patients $(83.33 \%)$ had PSA levels of $>51 \mathrm{ng} / \mathrm{ml}, 27$ patients who were benign on HPE correlation patients had PSA levels between 4-50 $\mathrm{ng} / \mathrm{ml}$. In our study (Table 1) with serum PSA levels 4-10 ng/ml, TRUS guided biopsy detected cancer in $11.1 \%$ cases, while the detection rate was $0 \%$ with serum PSA levels $11-20 \mathrm{ng} / \mathrm{ml}, 16.75 \%$ levels of $21-30 \mathrm{ng} / \mathrm{ml}, 25 \%$ with levels of $41-50 \mathrm{ng} / \mathrm{ml}$ and detection rate was $100 \%$ with serum PSA levels of $>51 \mathrm{ng} / \mathrm{ml}$. This data showed a strong correlation of PSA level with tumour diagnosis, statistically significant was very much significant with $p$ value of 0.000 . A study by Lojanapiwat, et al $^{18}$ also demonstrated specificity of PSA levels of 4-10,10.1-20,21-50,50-100 and $>100 \mathrm{ng} / \mathrm{ml}$ in the diagnosis of prostate cancer was 9.3, 55.5, 87.5, 98.2 and 99.7 respectively. Other studies by Ahmed Alghazo et al ${ }^{19}$ showed PSA levels between 4-10 ng/ml, between 10-20 $\mathrm{ng} / \mathrm{ml}$ and above $20 \mathrm{ng} / \mathrm{ml}$, the cancer detection rate by TRUS guided biopsy was $20.6 \%, 32.4 \%$ and $47 \%$ respectively. In study by Hyeon Jeong et $\mathrm{al}^{20}$ cancer detection rate was $34 \%$ with serum PSA level of $10-20 \mathrm{ng} / \mathrm{ml}$.

\begin{tabular}{|c|c|c|c|c|}
\hline \multirow{2}{*}{ Serum PSA Levels } & \multicolumn{2}{|c|}{ Histopathology } & \multirow{2}{*}{ Total } \\
\cline { 3 - 4 } & & Benign & Malignant & \\
\hline $4-10 \mathrm{ng} / \mathrm{ml}$ & Count (\%) & $8(88.9 \%)$ & $1(11.1 \%)$ & $9(100.0 \%)$ \\
\hline $11-20 \mathrm{ng} / \mathrm{ml}$ & Count (\%) & $8(100.0 \%)$ & $0(0.0 \%)$ & $8(100.0 \%)$ \\
\hline $21-30 \mathrm{ng} / \mathrm{ml}$ & Count (\%) & $5(83.3 \%)$ & $1(16.7 \%)$ & $6(100.0 \%)$ \\
\hline $31-40 \mathrm{ng} / \mathrm{ml}$ & Count (\%) & $3(100.0 \%)$ & $0(0.0 \%)$ & $3(100.0 \%)$ \\
\hline $41-50 \mathrm{ng} / \mathrm{ml}$ & Count (\%) & $3(75.0 \%)$ & $1(25.0 \%)$ & $4(100.0 \%)$ \\
\hline$>51 \mathrm{ng} / \mathrm{ml}$ & Count (\%) & $0(0.0 \%)$ & $6(100.0 \%)$ & $6(100.0 \%)$ \\
\hline \multicolumn{7}{|c|}{ Total } & Count (\%) & $\mathbf{2 7 ( 7 5 . 0 \% )}$ & $\mathbf{9 ( 2 5 . 0 \% )}$ & $\mathbf{3 6 ( 1 0 0 . 0 \% )}$ \\
\hline \multicolumn{3}{|c|}{ Table 4. Correlation between PSA Levels and HPE } \\
\hline
\end{tabular}

\begin{tabular}{|c|c|c|c|c|c|c|}
\hline & Value & df & $\begin{array}{c}\text { Asymp. Sig. } \\
\text { (2-sided) }\end{array}$ & $\begin{array}{c}\text { Exact Sig. } \\
\text { (2-sided) }\end{array}$ & $\begin{array}{c}\text { Exact Sig. } \\
\text { (1-sided) }\end{array}$ & $\begin{array}{c}\text { Point } \\
\text { Probability }\end{array}$ \\
\hline $\begin{array}{c}\text { Pearson } \\
\text { Chi-Square }\end{array}$ & $22.815^{\mathrm{a}}$ & 5 & .000 & .000 & - & - \\
\hline $\begin{array}{c}\text { Likelihood } \\
\text { Ratio }\end{array}$ & 24.304 & 5 & .000 & .000 & - & - \\
\hline $\begin{array}{c}\text { Fisher's Exact } \\
\text { Test }\end{array}$ & 18.389 & & & .000 & - & - \\
\hline \multicolumn{7}{|c|}{ Table 4a. Correlation between PSA Levels and HPE } \\
\hline
\end{tabular}

\section{Correlation of Complications Post TRUS Biopsy}

Out of 36 patients who had the procedure under local anaesthetic none of the patients had post procedure complications like rectal bleeding, need for anaesthesia or prolongation of hospitalization. Similar studies by Tobiume et $\mathrm{al}^{21}$ none of the patients showed rectal bleeding or need for anaesthesia, only few patients had minor complications.

\section{Gleason Score}

In our study a Gleason score of 7 was noted in $61 \%$ of malignant cases. Similar studies like Kumari K, Baru R ${ }^{23}$ and Song et al ${ }^{24}$ revealed a Gleason score of 7 in $51.61 \%$ cases and 6 in $60 \%$ of patients respectively.

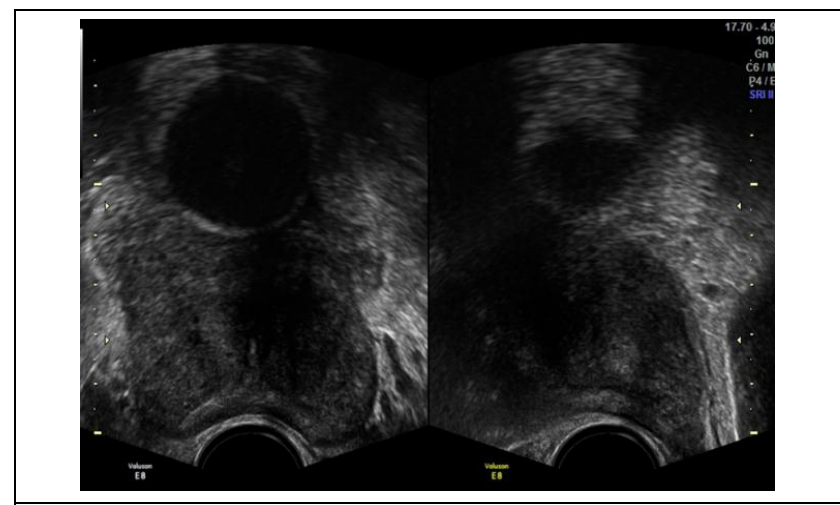

Figure 1. TRUS Image of 65-Year-Old Showed Enlarged Prostate with Heterogenous Echotexture with Focal Hypoechogenic Lesion in the Left Lobe, Biopsy was Suggestive of Adenocarcinoma of Prostate

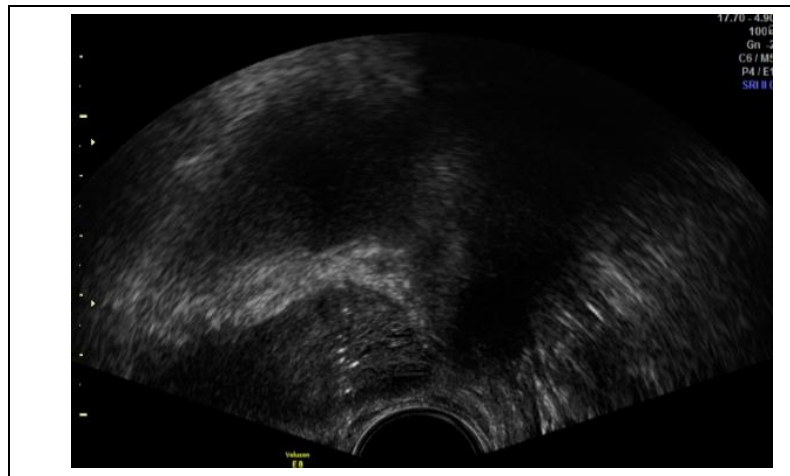

Figure 2. TRUS Image of 48-Year-Old Shows the Path of the Biopsy Needle

\section{DISCUSSION}

Analysis of collected data and interpretation data in comparison to other studies. In our study trans rectal ultrasound guided needle core sextant biopsy with histopathological evaluation was done. We evaluated 36 subjects between age groups of 40-90 yrs. from November 2014 to July 2016 at Yenepoya Medical Hospital, Deralakatte, Mangalore.

The incidence of prostate cancer differs internationally with the lowest incidence being in Southeast Asia. ${ }^{8}$ Over the past two decades the incidence of prostate cancer has increased significantly 9 and is the most commonly diagnosed cancer in males. ${ }^{10}$ In today's competitive world the need for improving current standards of medical care is one of the top most priorities and in order to fulfil this essential goal various modalities of investigations being developed and their efficacies studied. The diagnosis of a clinically enlarged prostrate is confirmed by the radiologist on the basis of an enlarged prostate either with ultrasound or threedimensional diagnostic imaging studies of the male pelvis. Prostatic biopsy is one of the most important investigations for diagnosing and excluding prostate cancer by histological analysis and was first described in 1937 by Astraldi. In view of this we decided to study the co-relation of TRUS and histopathological findings in diagnosing prostatic diseases. 


\section{CONCLUSIONS}

TRUS guided sextant core biopsy is a safe and effective procedure in diagnosing prostate cancer and has high diagnostic rates for patients with PSA levels of $>50 \mathrm{ng} / \mathrm{ml}$ and gland volume between $30-50 \mathrm{cc}$.

\section{Limitations}

It's a short-term study hence long-term changes in the prostate are not studied in the younger population. The size of the study population was very small and sample size was very low. Long term follow-up of those patients with elevated serum PSA and normal HPE is necessary.

\section{REFERENCES}

[1] Gupta NP, Ansari MS, Dass SC. Transrectal ultrasound guided biopsy for detecting early prostate cancer: an Indian experience. Indian Journal of Cancer 2005;42(3):151-4.

[2] Applewhite JC, Matlaga BR, McCullough DL, et al. Transrectal ultrasound and biopsy in early diagnosis of prostate cancer. Cancer Control 2001;8(2):141-50.

[3] Takahashi H, Ouchi T. The ultrasonic diagnosis in the field of urology. Proc Jpn Soc Ultrasonics Med 1963;3:7.

[4] Watanabe H, Igari D, Tanahasi Y, et al. Development and application of new equipment for transrectal ultrasonsgraphy. J Clin Ultrasound 1974;2(2):91-8.

[5] Astraldi A. Diagnosis of cancer of the prostate: biopsy by rectal route. Urol Cutan Rev 1937;41:421.

[6] Wild JJ, Reid JM. Progress in techniques of soft tissue examination by 15 MC pulsed ultrasound in biology and medicine: a symposium sponsored by the Bioacoustics Laboratory of University of Illinos. Washington, DC: American Institute of Biological Sciences 1957:30-45.

[7] Hodge KK, McNeal JE, Terris MK, et al. Random systematic versus directed ultrasound guided transrectal core biopsies of the prostate. J Urol 1989;142(1):71-5.

[8] Hsing AW, Tsao L, Devesa SS. International trends and patterns of prostate cancer incidence and mortality. Int J Cancer 2000;85(1):60-7.

[9] Parkin DM, Bray F, Ferlay J, et al. Global cancer statistics, 2002. CA Cancer J Clin 2005;55(2):74-108.

[10] McCaul KA, Luke CG, Roder DM. Trends in prostate cancer incidence and mortality rates in South Australia, 1977-1993. Med J Aust 1995;162(10):520-2.
[11] Berry SJ, Coffey DS, Walsh PC, et al. The development of human benign prostatic hyperplasia with age. J Urol 1984;132(3):474-9.

[12] Okani C, Akang E, Ogunbiyi O. Incidence of sub-clinical prostatic disease at autopsy in the university college hospital, Ibadan. Open Journal of Urol 2013;3(2):80-6.

[13] Suzuki K. Epidemiology of prostate cancer and benign prostatic hyperplasia. JMAJ 2009;52(6):478-83.

[14] Levine MA, Ittman M, Melamed J, et al. Two consecutive sets of transrectal ultrasound guided sextant biopsies of the prostate for the detection of prostate cancer. J Urol 1998;159(2):471-5.

[15] Karakiewicz PI, Bazinet M, Aprikian AG, et al. Outcome of sextant biopsy according to gland volume. Urol 1997;49(1):55-9.

[16] Burks DD, Drolshagen LF, Fleischer AC, et al. Transrectal sonography of benign and malignant prostatic lesions. AJR Am J Roentgenol 1986;146(6):1187-91.

[17] Hong CG, Yoon BI, Choe HS, et al. The prevalence and characteristic differences in prostatic calcification between health promotion center and urology department outpatients. Korean J Urol 2012;53(5):3304.

[18] Lojanapiwat B, Anutrakulchai W, Chongruksut W, et al. Correlation and diagnostic performance of the prostatespecific antigen level with the diagnosis, aggressiveness and bone metastasis of prostate cancer in clinical practice. Prostate Int 2014;2(3):133-9.

[19] Elabbady AA, Khedr MM. Extended 12-Core prostate biopsy increases both the detection of prostate cancer and the accuracy of Gleason Score. Eur Urol 2006;49(1):49-53.

[20] Jeong H, Jeong B, Kwak C, et al. A comparison of prostate cancer detection rates by 12 or 6 core biopsy at different prostate-specific antigen densities in Korean men. World J Urol 2008;26(4):395-400.

[21] Tobiume M, Yamada Y, Nakamura K, et al. Retrospective study comparing six - and twelve-core prostate biopsy in detection of prostate cancer. Int Braz J Urol 2008;34(1):9-14.

[22] Kumari K, Durga, Baru R. Transrectal ultrasound guided needle core biopsy of prostatic lesions. IJHSR 2014;4(3):142-8.

[23] Song C, Ro J, Lee M, et al. Prostate cancer in Korean men exhibits poor differentiation and is adversely related to prognosis after radical prostatectomy. Urol 2006;68(4):820-4. 